\title{
EFEITO DO PRÉ-RESFRIAMENTO EM SALMOURA NA FORMAÇÃO DE MARTENSITA DURANTE A LAMINAÇÃO PILOTO DE AÇO INOXIDÁVEL AUSTENÍTICO 201LN*
}

\author{
Camila Oliveira de Souza ${ }^{1}$ \\ Carolline Serafim da Silva ${ }^{2}$ \\ Juciane Maria Alves ${ }^{3}$ \\ Andersan dos Santos Paula ${ }^{4}$ \\ Luiz Paulo Mendonça Brandão ${ }^{5}$ \\ Saulo Brinco Diniz ${ }^{6}$ \\ Isabela Santana de Oliveira ${ }^{7}$
}

\section{Resumo}

O material em estudo consistiu em um aço inoxidável austenítico 201LN, na forma de chapa com aproximadamente $5,00 \mathrm{~mm}$ de espessura na condição laminada a quente. As etapas de processamento adotadas neste estudo consistiram em laminação a temperatura ambiente e pré-resfriamento em salmoura, com o objetivo de avaliar a formação de martensita e evolução da resistência mecânica do material. As técnicas de caracterização utilizadas foram macro Dureza Rockwell C (HRC), Ferritoscopia e Difração de Raios-X (DRX). Os resultados preliminares mostraram que tanto a fração volumétrica de martensita formada, como a dureza, foram maiores nas amostras submetidas a maiores percentuais de redução e préresfriamento em salmoura.

Palavras-chave: Aço Inoxidável Austenítico; Laminação a frio; Martensita; Efeito TRIP.

\section{PRE-COOLED IN BRINE EFFECT IN MARTENSITE FORMATION DURING THE PILOT ROLLING OF 201LN AUSTENITIC STAINLESS STEEL}

\section{Abstract}

The studied material consists in a $201 \mathrm{LN}$ austenitic stainless steel, as a sheet with approximately $5.00 \mathrm{~mm}$ thickness in the hot rolled condition. The processing steps adopted in this study consisted of rolling at room temperature and pre-cooled in brine, in order to evaluate the martensite formation and the mechanical strength evolution. The characterization techniques used were macro Hardness Rockwell C (HRC), Ferritoscopy and X-ray Diffraction (XRD). Preliminary results showed that martensite volumetric fraction formed and the Hardness were higher in the samples that were subjected to higher thickness reduction and pre-cooled in brine.

Keywords: Austenitic Stainless Steel; Cold Rolling; Martensite; TRIP effect.

1 Eng. Metalurgista, M.Sc., Doutoranda em Ciência dos Materiais (PGCM / SE-4), Instituto Militar de Engenharia (IME), Rio de Janeiro, RJ, Brasil.

2 Eng. Metalurgista, M.Sc., Analista da Garantia da Qualidade Jr., Galvasud, Porto Real, RJ, Brasil.

3 Química, M.Sc., Doutoranda em Ciência dos Materiais (PGCM / SE-4), IME, Rio de Janeiro, RJ, Brasil

4 Eng. Metalurgista, M.Sc., D.Sc., Professora Adjunta (PGCM / SE-4), IME, Rio de Janeiro, RJ, Brasil.

5 Eng. Metalurgista, M.Sc., D.Sc., Professor Associado (PGCM / SE-4), IME, Rio de Janeiro, RJ, Brasil.

6 Eng. Metalurgista, M.Sc., Doutorando em Ciências dos Materiais (PGCM / SE-4), IME, Rio de Janeiro, RJ; Professor DI - 1, CEFET - Angra dos Reis, Angra dos Reis, RJ, Brasil.

7 Eng. Mecânica, M.Sc., Universidade Federal Fluminense (UFF), Volta Redonda, RJ. 


\section{INTRODUÇÃO}

Os aços inoxidáveis austeníticos (AIAs) possuem austenita estável devido a alguns elementos presentes e endurecem por deformação a frio. Tal endurecimento devese à fase austenítica que se transforma em martensita e/ou ao encruamento da austenita em função da temperatura, modo e taxa de deformação [1].

Elementos de liga podem ser adicionados aos aços inoxidáveis austeníticos. 0 manganês favorece a solubilidade do nitrogênio no aço, permitindo a formação de uma família de aços inoxidáveis com baixo teor de níquel e com alto teor de manganês e nitrogênio, visando diminuir o custo global do mesmo. Esta família de aços é conhecida como AIAs da série 200 e são utilizados em aplicações estruturais e como utensílios de cozinha. A resistência à corrosão destas ligas é inferior a dos aços da série 300 .

De acordo com a composição química dos AIAs, estes podem apresentar uma característica particular: Transformação de fase induzida por plasticidade, efeito TRIP (ou do inglês, Transformation Induced Plasticity), tal efeito é visado por conceder ao aço propriedades mecânicas como alta resistência, ductilidade e tenacidade [2].

É fundamental a compreensão da influência da tensão elástica e da deformação plástica no processo de transformação martensítica por efeito TRIP. Como mostrado na Figura 1, a aplicação de uma tensão em uma temperatura que não esteja muito


nucleação de martensita. Este fenômeno é denominado nucleação assistida por tensão [3].



Figura 1. Relação tensão versus temperatura e influência da tensão elástica e deformação plástica no efeito TRIP [3].

A nucleação induzida por deformação se dá quando determinado material está em uma temperatura do campo austenítico (entre $\mathrm{M}_{\mathrm{i} \sigma}$ e $\mathrm{M}_{\mathrm{d}}$ ) e um nível de tensão acima da tensão de escoamento aplicado ao mesmo, incrementando a energia livre da austenita. No entanto, se a temperatura na qual o material encontra-se é abaixo de $\mathrm{M}_{\mathrm{i}_{\sigma}}$ e acima de $\mathrm{Mi}_{\mathrm{i}}$, será suficiente um nível de tensão abaixo da de escoamento plástico do material para ter a nucleação de martensita induzida por tensão no campo elástico de deformação. A transformação martensítica ocorre até a proximidade da temperatura $M_{d}$, máxima temperatura na qual há a formação de martensita induzida por plasticidade.

Estimar $\mathrm{M}_{\mathrm{i} \sigma}$ e $\mathrm{M}_{\mathrm{d}}$ são procedimentos complexos, contudo a temperatura $\mathrm{M}_{i}$ pode ser estimada através de equações empíricas baseadas em composição química, como a exemplo de Mi na Equação 1 [4]. 


$$
\mathrm{Mi}\left({ }^{\circ} \mathrm{C}\right)=1305-1665(\% \mathrm{C}+\% \mathrm{~N})-28(\% \mathrm{Si})-33(\% \mathrm{Mn})-42(\% \mathrm{Cr})-61(\% \mathrm{Ni})
$$

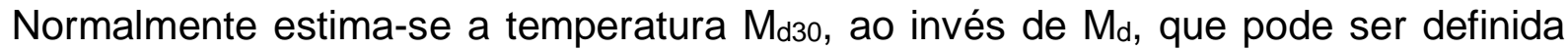
como a temperatura na qual $50 \%$ de martensita é produzida após aplicação de $30 \%$ de deformação verdadeira, sendo esta inferior à temperatura $M_{d}$. Uma de suas representações mais comuns, Equação 2, foi estabelecida por Angel e posteriormente modificada por Nohara (Equação 3) com o acréscimo da contribuição do tamanho de grão ASTM (TG) [4].

$$
\begin{aligned}
& \mathrm{Md}_{\mathrm{d} 30}\left({ }^{\circ} \mathrm{C}\right)-\mathrm{ANGEL}=413-462(\% \mathrm{C}+\% \mathrm{~N})-9,2(\% \mathrm{Si})-8,1(\% \mathrm{Mn})- \\
& 13,7(\% \mathrm{Cr})-9,5(\% \mathrm{Ni})-18,5(\% \mathrm{Mo}) \\
& \mathrm{Md}_{\mathrm{d} 30}\left({ }^{\circ} \mathrm{C}\right)-\mathrm{NOHARA}=551-462(\% \mathrm{C}+\% \mathrm{~N})-9,2(\% \mathrm{Si})-8,1(\% \mathrm{Mn})- \\
& 13,7(\% \mathrm{Cr})-29(\% \mathrm{Ni}+\% \mathrm{Cu})-18,5(\% \mathrm{Mo})-68(\% \mathrm{Nb})-1,42(\mathrm{TG}-8)
\end{aligned}
$$

A transformação de austenita ( $\gamma$ ) em martensita ocorre por processo de cisalhamento, sem haver difusão [5]. Dois tipos de martensita podem ser formados nos aços inoxidáveis austeníticos: A martensita $\varepsilon$ (hexagonal compacta, HCP) e martensita $\alpha^{\prime}$ (cúbica de corpo centrado, CCC). As fases $\varepsilon$ e a' são metaestáveis e podem ser revertidas à austenita se aquecidas à temperatura abaixo da temperatura de recristalização. A ocorrência e a quantidade de ambos os tipos de martensita $\varepsilon \mathrm{e}$ a' dependem de uma série de fatores, como: Composição do aço, energia de falha de empilhamento (EFE), temperatura, taxa e modo de deformação [6].

No que se refere à composição química, os efeitos dos elementos de liga nos aços e ligas especiais não alteram somente as fases ou constituintes presentes em equilíbrio, mas também no modo e na velocidade com que as fases se formam. A presença de elementos de liga pode alterar a característica própria das fases presentes [7].

Outro fator importante é a energia de falha de empilhamento (EFE), pois a mesma influencia diretamente na microestrutura formada. Para altos valores de EFE, espera-se a formação de uma microestrutura sem ocorrência de martensita induzida por deformação, ou tensão, isto é, não há a formação das martensitas $\varepsilon$ e a' [8]. Os AlAs são conhecidos por terem baixa EFE, quando comparados aos outros metais com estrutura CFC, coexistindo tanto a martensita $\varepsilon$, como a $\alpha$ ', sendo a primeira normalmente vinculada aos estágios com baixos percentuais de deformação e composições que resultem em uma EFE no limite superior.

Hamada e colaboradores (2013) realizaram um estudo para avaliar o efeito da taxa de deformação em aços 201 e 201L. Os materiais foram submetidos a um ensaio de tração uniaxial e verificaram que a tensão de escoamento é dependente da taxa de deformação, assim uma maior taxa de deformação resulta em valores mais altos para a tensão de escoamento. Foi possível concluir que o mecanismo de deslizamento de discordâncias controla a deformação inicial em todas as temperaturas. $\mathrm{O}$ aço $201 \mathrm{~L}$ exibe uma fração de martensita ligeiramente superior ao aço 201 [9].

Há estudos a respeito da transformação de fase dos AIAs 304 por meio de diferentes modos de deformação, tais como: ensaio de tração, ensaio de torção e ensaio de compressão. Padilha e Guedes (1994) concluíram que, durante o ensaio de tração, ocorre um gradiente de deformação e um gradiente de velocidade de deformação ao longo do corpo de prova, causando um considerável gradiente de temperatura e que a quantidade de martensita $\alpha^{\prime}$ formada em ensaio de tração 
aumenta com o aumento da deformação [10]. Outro estudo, realizado por Lebedev (2000), mencionou que a deformação por tração provoca a formação mais intensa de ambos os tipos de martensita, $\varepsilon$ e $\alpha^{\prime}$, do que a deformação por torção e compressão, com a mesma deformação efetiva [11].

O objetivo deste trabalho consistiu em avaliar a evolução da transformação martensítica de um aço inoxidável austenítico $201 \mathrm{LN}$ e seu comportamento referente ao endurecimento, mediante percentuais de redução na laminação pré-definidos. A laminação a frio foi realizada sob 2 condições: com o material a temperatura ambiente e com pré-resfriamento em salmoura.

De modo a atender os objetivos propostos, as amostras do aço em estudo no estado como recebido (laminado a quente) e com deformações de 40, 60 e 80\%, laminadas a temperatura ambiente e pré-resfriadas em salmoura, foram submetidas às análises de Ferritoscopia e Difração de Raios-X (DRX), com o intuito de quantificar as fases presentes no material e análise de macrodureza (Rockwell $\mathrm{C}$ ), com o intuito de avaliar o grau de endurecimento. Os resultados das análises foram correlacionados com as reduções de espessura resultantes da laminação. No que diz respeito à técnica de DRX utilizaram-se dois métodos para quantificação das fases: Somatório dos picos de todas as fases e Método dos picos mais intensos de cada fase.

\section{MATERIAL E MÉTODOS}

O material em estudo consistiu em um aço inoxidável austenítico 201LN, na forma de chapas fornecidas pela empresa APERAM South América com aproximadamente $5 \mathrm{~mm}$ de espessura na condição laminada a quente. A composição química deste material está descrita na Tabela 1.

Tabela 1. Composição química (\% em peso) do aço inoxidável austenítico $201 \mathrm{LN}$ fornecido pela APERAM South América.

\begin{tabular}{|c|c|c|c|}
\hline $\begin{array}{c}\text { Elementos } \\
\text { (\% em peso) }\end{array}$ & Valores & $\begin{array}{c}\text { Elementos } \\
\text { (\% em } \\
\text { peso) }\end{array}$ & Valores \\
\hline$C$ & 0,03 & Co & 0,0463 \\
\hline $\mathrm{Mn}$ & 6,9078 & $\mathrm{~V}$ & 0,0428 \\
\hline $\mathrm{Si}$ & 0,3088 & $\mathrm{Nb}$ & 0,0224 \\
\hline $\mathrm{P}$ & 0,0381 & $\mathrm{~Pb}$ & 0,0073 \\
\hline$S$ & 0,0009 & $B$ & 0,0006 \\
\hline $\mathrm{Cr}$ & 17,0043 & $\mathrm{Ti}$ & 0,0058 \\
\hline $\mathrm{Ni}$ & 4,0093 & Sn & 0,0029 \\
\hline Mo & 0,0188 & $W$ & 0,0117 \\
\hline $\mathrm{Al}$ & 0,0034 & $\mathrm{~N}$ & 0,2000 \\
\hline
\end{tabular}

O aço inoxidável austenítico $201 \mathrm{LN}$ foi inicialmente laminado em temperatura ambiente e pré-resfriado a cada passe em salmoura (aproximadamente $-5^{\circ} \mathrm{C}$ ), com o intuito de investigar o comportamento da transformação martensítica induzida por deformação em temperaturas distintas e minimizar o incremento de temperatura gerado pela trabalho mecânico resultante de cada passe de redução na laminação. Foram laminados corpos de provas com reduções de espessura de 40,60 e $80 \%$ e deformação com aproximadamente $10 \%$ de redução a cada passe. O processo de laminação foi realizado nas dependências do Laboratório de Tratamento 
Termomecânico do Instituto Militar de Engenharia (IME) no laminador piloto FENN MFG, modelo D-51719:1973, o qual operou em configuração duo com cilindros de diâmetro 133,70 mm.

As amostras laminadas (40, 60 e $80 \%$ ) e a amostra no estado como recebido (CR) foram submetidas inicialmente à técnica de Ferritoscopia. Para isto, foram traçadas duas linhas centrais (horizontal e vertical) na superfície das amostras, em relação à direção de laminação (DL) e direção transversal (DT), com distanciamento de $1 \mathrm{~cm}$ entre as medidas. As análises foram efetuadas nas dependências da Escola de Engenharia Industrial Metalúrgica de Volta Redonda (UFF) com o auxílio do ferritoscópio FISCHER - FMP30, cuja sensibilidade de detecção da fase ferromagnética varia desde 0,1 a $80 \%$. Para a realização de tal técnica não se fez necessária a preparação prévia após a laminação.

Em seguida, foram realizadas as medidas vias técnicas de dureza e DRX. Na Tabela 2 é mostrado o resumo das etapas de preparação das amostras para estas técnicas.

Tabela 2. Resumo das etapas de preparação das amostras para as técnicas de Dureza e DRX.

\begin{tabular}{c|l}
\hline Caracterização & \multicolumn{1}{c}{ Preparação } \\
\hline Dureza & $\begin{array}{l}\text { As amostras foram cortadas com dimensões de 2,5 x } \\
2,5 \mathrm{~cm}(\mathrm{DL} \times \mathrm{DT}), \text { em uma máquina de corte Discotom } \\
\text { com disco abrasivo de carbeto de silício, para análise } \\
\text { da seção transversal associada à direção de } \\
\text { laminação. }\end{array}$ \\
\hline Dureza & $\begin{array}{l}\text { Preparação metalográfica mecânica da superfície de } \\
\text { análise iniciada com lixamento mecânico, utilizando } \\
\text { lixas metalográficas de granulometrias de } 360,600 \text { e }\end{array}$ \\
\hline DRX & $\begin{array}{l}\text { Polimento eletrolítico utilizando uma solução } \\
\text { composta por ácido perclórico (5 mL), água destilada } \\
(10 \text { mL) álcool etílico absoluto (75 mL) à } \\
\text { temperatura ambiente, com voltagem variando entre } \\
20 \text { e 25 } \mathrm{V} \text { e tempos de imersão variando de 10 a 25 s. } \\
\text { Estas variações foi devido às condições do } \\
\text { experimento e as dimensões das amostras } \\
\text { analisadas. }\end{array}$ \\
\hline
\end{tabular}

Para o ensaio de dureza se fez uso de um durômetro Rockwell C com penetrador cônico de diamante, pré-carga de $10 \mathrm{kgf}$ por $15 \mathrm{~s}$ e uma carga de $150 \mathrm{kgf}$, instalado no laboratório de Ensaios Mecânicos do IME. Foram realizadas 10 medidas ao longo do plano da chapa, para cada condição estudada. Já as medidas relativas à técnica de DRX, foram realizadas no laboratório de Difração de Raios-X do IME utilizandose o difratômetro de Raios-X, modelo X'PERT PRO MRD da PANalytical, com um step size de 0,0197, ângulos inicial de 30,00으 e final de 129,99을 e tempo total de análise de aproximadamente 1 h e 7 min para cada amostra.

\section{RESULTADOS E DISCUSSÃO}

As temperaturas $M_{i}$ e Md30 do aço 201LN foram estimadas através das Equações 1 e 2, mencionadas anteriormente, e as energias de falha de empilhamento (EFE) foram calculadas a partir das Equações 4 e 5 [9]:

$$
\begin{aligned}
& \text { EFE }\left(\mathrm{mJ} / \mathrm{m}^{2}\right)-\text { BROFMAN E ANSELL }=16,7+2,1(\% \mathrm{Ni})- \\
& 0,9(\% \mathrm{Cr})+26(\% \mathrm{C})
\end{aligned}
$$




$$
\begin{aligned}
& \text { EFE }\left(\mathrm{mJ} / \mathrm{m}^{2}\right)-\mathrm{PICKERING}=25,7+2(\% \mathrm{Ni})+410(\% \mathrm{C})- \\
& 0,9(\% \mathrm{Cr})-77(\% \mathrm{~N})-13(\% \mathrm{Si})-1,2(\% \mathrm{Mn})
\end{aligned}
$$

Observou-se que nas equações empíricas apresentadas, os elementos $\mathrm{Cr}$, $\mathrm{Ni}$ e $\mathrm{C}$ contribuem significativamente na EFE de um AIAs. O carbono possui uma maior contribuição na equação de Pickering.

$\mathrm{Na}$ Tabela 3 são mostrados os valores das temperaturas de transformação martensítica e EFE calculados, em função da composição química do aço estudado.

Tabela 3. Valores das temperaturas de transformação martensítica e EFE calculados em função da composição química do aço estudado.

\begin{tabular}{l|c|c|c|c}
\hline Material & $\mathbf{M}_{\mathrm{i}}\left({ }^{\circ} \mathbf{C}\right)$ & $\begin{array}{c}\mathbf{M}_{\mathrm{d} 30}\left({ }^{\circ} \mathrm{C}\right)- \\
\text { Angel }\end{array}$ & $\begin{array}{c}\text { EFE }\left(\mathbf{m J} / \mathbf{m}^{2}\right)-\text { Brofman e } \\
\text { Ansell }\end{array}$ & $\begin{array}{c}\mathrm{EFE}\left(\mathbf{m J} / \mathbf{m}^{2}\right)- \\
\text { Pickering }\end{array}$ \\
\hline $201 \mathrm{LN}$ & $-273,30$ & $-23,45$ & 10,59 & 3,01 \\
\hline
\end{tabular}

Ao se estimar a temperatura $\mathrm{Mi}_{\mathrm{i}}$ (Equação 1) do aço 201LN, o valor apresentou-se abaixo do zero Kelvin absoluto $\left(-0,15^{\circ} \mathrm{C}\right)$. Desta forma, a equação utilizada não é válida para estimar a temperatura $\mathrm{M}_{\mathrm{i}}$ na faixa de composição desta liga. Com o intuito de se estimar esta temperatura e criticar a equação anterior, a Equação 6 foi utilizada [12] .

$$
\begin{aligned}
& M_{i}[\mathrm{~K}]=1578-41,7(\% \mathrm{Cr})-61,1(\% \mathrm{Ni})-33,3(\% \mathrm{Mn})-27,8(\% \mathrm{Si})-36,1(\% \mathrm{Mo})- \\
& 1667(\% \mathrm{C}+\% \mathrm{~N}) \\
& \mathrm{Mi}_{i}=3,32 \mathrm{~K} \text { ou }-269,83^{\circ} \mathrm{C}
\end{aligned}
$$

A fração volumétrica de martensita formada foi detectada e quantificada via Ferritoscopia para todas as condições em estudo, inclusive a CR (como recebida). Foi possível correlacioná-la com as deformações impostas, tanto para as amostras laminadas em temperatura ambiente como para as pré-resfriadas em salmoura. $\mathrm{Na}$ Figura 2 está ilustrado o gráfico desta correlação.

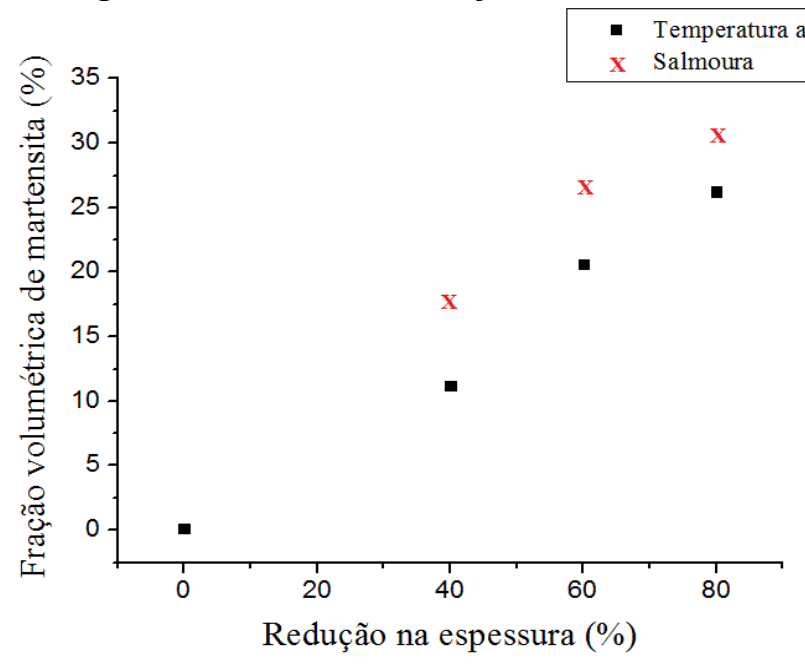

Figura 2. Evolução da fração volumétrica de martensita em função da redução na espessura para as amostras na condição $\mathrm{CR}$, laminadas em temperatura ambiente e pré-resfriadas em salmoura. 
Observou-se que o material como recebido não era $100 \%$ austenítico, apresentando uma fração residual de martensita de $0,12 \%$ em função, provavelmente de esforços mecânicos associados às etapas de bobinamento e desbobinamento no fim de seu processamento industrial, tendo em vista que foi fornecido na condição laminada a quente.

O material 201LN no estado como recebido (CR) e com as reduções de 40, 60 e $80 \%$, laminado em temperatura ambiente (TA) e pré-resfriado em salmoura (SAL) foi avaliado pela técnica de DRX com o intuito de identificar e quantificar as fases presentes. O difratograma da amostra CR está representado na Figura 3.



Figura 3. Difratograma do aço $201 \mathrm{LN}$ na condição como recebida (CR) obtido com radiação de Co Ka.

A amostra como recebida apresentou somente picos associados à austenita, sendo o primeiro deles referente ao plano (111), o mais intenso. Não foram identificados picos associados à martensita e à ferrita delta, fases que poderiam ter sido induzidas ou remanescentes de alguma etapa de processamento para obtenção do material laminado a quente.

A quantificação das fases foi realizada pelas técnicas de Ferritoscopia e DRX. Pela primeira técnica encontrou-se um percentual residual de martensita de $0,12 \%$, enquanto que pela segunda, este aço foi considerado $100 \%$ austenítico, uma vez que nenhum pico associado à martensita foi identificado. A diferença de resultados entre as técnicas deve-se à metodologia de medição, pois a Difração de Raios- $X$ avalia uma camada superficial na ordem de mícrons enquanto que a Ferritoscopia abrange um maior volume do material. Além disso, as amostras avaliadas na análise de ferritoscopia não passaram por nenhuma preparação prévia de modo a remover a camada original da superfície do material. Enquanto que para a DRX a mesma foi lixada e posteriormente submetida ao polimento eletrolítico. Neste caso, o lixamento/polimento adotado pode ter removido alguma camada de martensita induzida superficialmente no material devido a alguma operação de bobinamento/desbobinamento da chapa durante a etapa de coleta de amostras para este estudo junto ao fornecedor. Os difratogramas das amostras processadas via laminação para este estudo são apresentados na Figura 4. 
Amostra 40TA



(A)

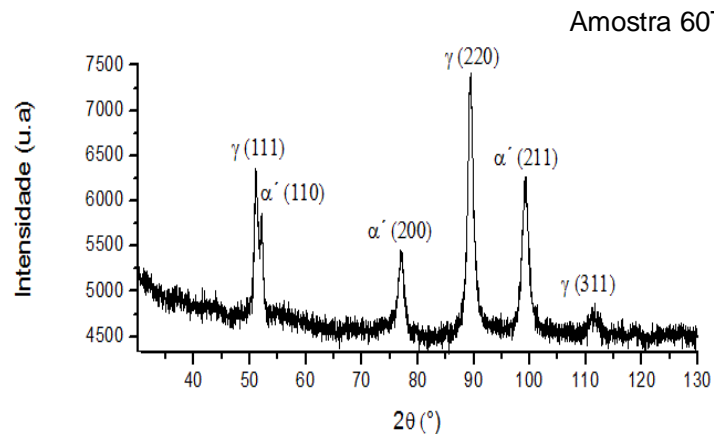

(C)

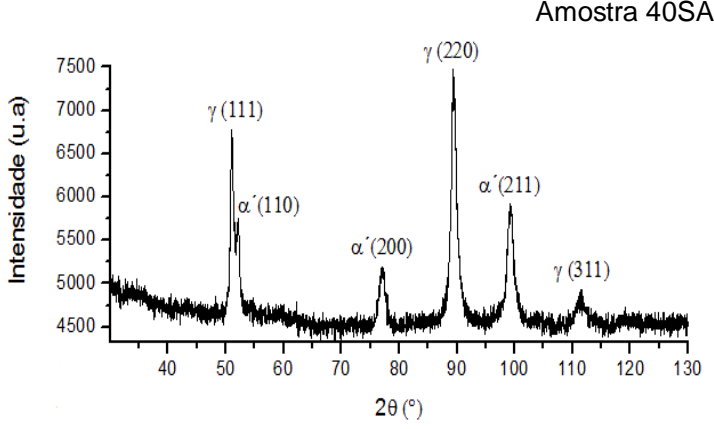

(B)

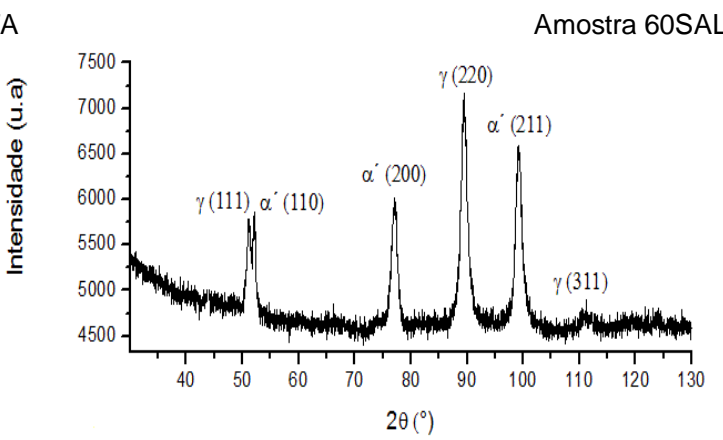

(D)



(E)

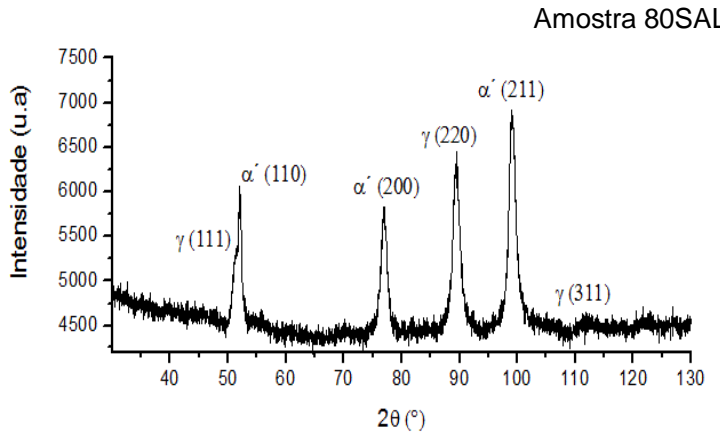

(F)

Figura 4. Difratogramas do aço $201 \mathrm{LN}$ laminado a frio com: $40 \%$ de deformação em temperatura ambiente $(A)$ e pré-resfriado em salmoura $(B) ; 60 \%$ de deformação em temperatura ambiente $(C)$ e pré-resfriado em salmoura (D) e $80 \%$ de deformação em temperatura ambiente (E) e pré-resfriado em salmoura $(F)$.

Para as amostras com $40 \%$ de redução foram observados picos mais intensos de austenita $(\gamma)$, sendo o (220) o mais intenso. Quando se refere à amostra préresfriada (B), pode-se verificar um pequeno aumento na intensidade do pico de martensita $\alpha^{\prime}(110)$ e um aumento maior no pico $\gamma(111)$.

De modo similar às amostras anteriores, quando se trata de $60 \%$ de redução, o pico $\gamma(220)$ continua sendo o mais intenso, porém há um decréscimo na sua intensidade com o pré-resfriamento (D). Nesta mesma condição, há um incremento na intensidade de $\alpha^{\prime}(200)$ e $\alpha^{\prime}(211)$ e um decréscimo nos picos $\gamma(111)$ e $\gamma(311)$.

Já na condição de pré-resfriamento em salmoura $(F)$ e com redução de $80 \%$, observou-se um aumento na intensidade dos picos $\alpha^{\prime}(110)$ e $\alpha^{\prime}(200)$ e uma diminuição na intensidade do pico $\gamma(220)$, porém o pico $\alpha^{\prime}(211)$ se tornou o mais intenso, quando comparado à amostra (E). Para ambas as amostras $E$ e $F$, o pico $\gamma(311)$ já não se torna tão pronunciado, quando comparado aos difratogramas anteriores. 
De um modo geral, com o progresso da deformação, verificou-se que os picos de $\gamma$ decresceram em suas intensidades, enquanto os picos de $\alpha^{\prime}$ incrementaram. Sendo que estas condições são ainda mais evidentes nas amostras que foram préresfriadas em salmoura, antes da laminação.

Após a identificação das fases por DRX, foi realizada a quantificação das mesmas por dois métodos: Somatório dos picos de ambas as fases e Método dos picos mais intensos de cada fase. Nas Tabelas 4, 5 e 6 são mostradas as frações volumétricas de austenita $(\mathrm{V} \gamma)$ e martensita $\left(\mathrm{V}_{\alpha^{\prime}}\right)$, para as amostras deformadas.

Tabela 4. Frações volumétricas de austenita $(\mathrm{V} \gamma)$ e martensita (Va') para as amostras com $40 \%$ de deformação em temperatura ambiente (40TA) e pré-resfriadas em salmoura (40SAL).

\section{Somatório dos picos de ambas as fases}

\begin{tabular}{c|c}
\hline 40TA & 40SAL \\
\hline $\mathrm{V}^{\prime}=21 \%$ & $\mathrm{~V}_{\alpha^{\prime}}=28 \%$ \\
$\mathrm{~V} \gamma=79 \%$ & $\mathrm{~V} \gamma=72 \%$ \\
\hline
\end{tabular}

Picos mais intensos de cada fase

\begin{tabular}{c|c}
\hline 40TA & 40 SAL \\
\hline $\mathrm{V}_{\alpha^{\prime}}=16 \%$ & $\mathrm{~V}_{\alpha^{\prime}}=19 \%$ \\
$\mathrm{~V} \gamma=84 \%=19 \%$ \\
\hline
\end{tabular}

Tabela 5. Frações volumétricas de austenita $(\mathrm{V} \gamma)$ e martensita $\left(\mathrm{V} \alpha^{\prime}\right)$ para as amostras com $60 \%$ de deformação em temperatura ambiente (60TA) e pré-resfriadas em salmoura (60SAL).

\section{Somatório dos picos de ambas as fases}

\begin{tabular}{c|c}
\hline 60TA & 60 SAL \\
\hline $\mathrm{V}_{\alpha^{\prime}}=34 \%$ & $\mathrm{~V}_{\alpha^{\prime}}=41 \%$ \\
$\mathrm{~V} \gamma=66 \%=5 \gamma=59 \%$ \\
\hline
\end{tabular}

Picos mais intensos de cada fase

\begin{tabular}{c|c}
\hline 60TA & $60 \mathrm{SAL}$ \\
\hline $\mathrm{V}_{\alpha^{\prime}}=23 \%$ & $\mathrm{~V}_{\alpha^{\prime}}=26 \%$ \\
$\mathrm{~V} \gamma=77 \% \mathrm{~V} \gamma=74 \%$ \\
\hline
\end{tabular}

Tabela 6. Frações volumétricas de austenita $(\mathrm{V} \gamma)$ e martensita $\left(\mathrm{V}^{\prime}\right)$ para as amostras com $80 \%$ de deformação em temperatura ambiente (80TA) e pré-resfriadas em salmoura (80SAL).

\section{Somatório dos picos de ambas as fases}

\begin{tabular}{c|c}
\hline 80TA & $80 \mathrm{SAL}$ \\
\hline $\mathrm{V}_{\alpha^{\prime}}=52 \%$ & $\mathrm{~V}_{\alpha^{\prime}}=59 \%$ \\
$\mathrm{~V}=48 \%$ & $\mathrm{~V}=41 \%$ \\
\hline
\end{tabular}

Picos mais intensos de cada fase

\begin{tabular}{c|c} 
80TA & 80SAL \\
$\mathrm{V}_{\alpha^{\prime}}=33 \%$ & $\mathrm{~V}_{\alpha^{\prime}}=34 \%$ \\
$\mathrm{~V}=67 \%$ & $\mathrm{~V} \gamma=66 \%$
\end{tabular}

Os resultados apresentados são coerentes, uma vez que com o aumento da deformação, aumentou a fração de martensita formada e decresceu a fração de austenita. Ao comparar ambos os métodos, verificou-se que o método do somatório dos picos de ambas as fases evidencia uma maior fração de martensita. 
O comportamento mecânico via Dureza Rockwell C (HRC) do aço 201LN, na condição como-recebido e após laminação em temperatura ambiente e préresfriamento em salmoura, é apresentado na Figura 5.

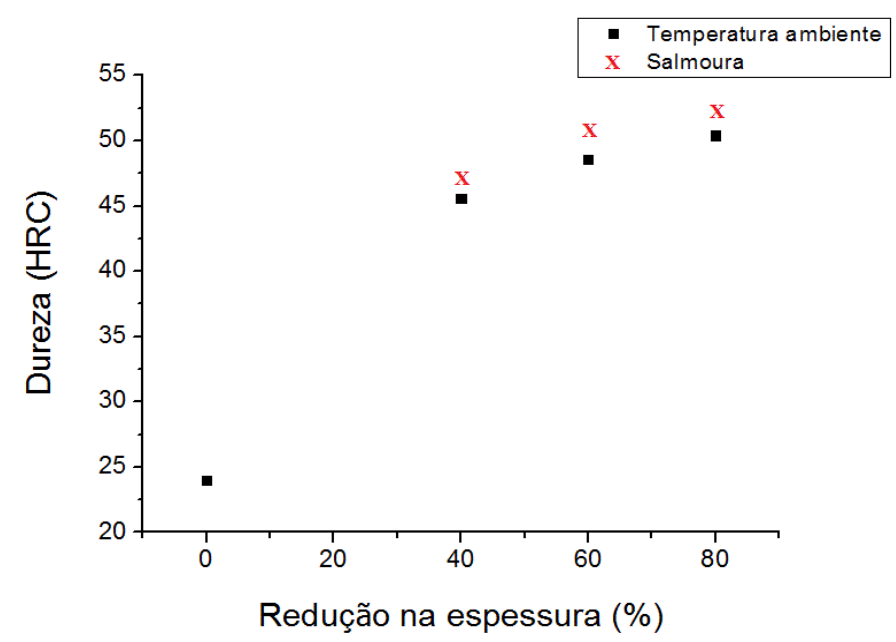

Figura 5. Comparação entre a dureza HRC e a redução na espessura para as amostras na condição $\mathrm{CR}$, laminadas em temperatura ambiente e pré-resfriadas em salmoura.

Observou-se que a diferença entre os dois processos de laminação em temperaturas distintas, foi maior para as reduções de 40 e $60 \%$, enquanto que para $80 \%$, a dureza foi praticamente a mesma. No que diz respeito à fração de martensita formada, há uma menor diferença entre as frações de martensita nas duas condições com esta mesma redução (Figura 3).

Além disso, notou-se nas Figuras 3 e 5, que há um incremento tanto na dureza como na fração de martensita formada quando se reduz a temperatura da amostra durante a laminação, porém esta diferença é mais significativa na fração de martensita obtida do que na dureza. No entanto, a escala Rockwell C de dureza não descreve tão bem a diferença entre os valores medidos, sendo interessante para a continuidade deste estudo a adoção de medidas de dureza na escala Vickers.

\section{CONCLUSÃO}

A partir dos resultados obtidos observou-se que em função da magnitude de redução em laminação e com o pré-resfriamento em salmoura, houve um incremento na fração volumétrica de martensita e um decréscimo na fração de austenita e isto foi verificado através das técnicas utilizadas, Ferritoscopia e DRX. Além da Ferritoscopia, a quantificação de fases foi realizada por dois diferentes métodos a partir dos difratogramas de DRX, sendo eles: Somatório dos picos de ambas as fases e Método dos picos mais intensos de cada fase. Ambos os métodos foram adotados como crítica metodológica devido a um estudo de evolução da textura do AISI $201 \mathrm{LN}$ que está sendo realizado, com o intuito de publicá-lo futuramente. Acredita-se que não seria adequado somente o uso do método do pico mais intenso, sendo que este só é válido para amostras com textura aleatória e neste momento, não se pode afirmar isto.

De forma análoga, a análise de Dureza Rockwell $C$ evidenciou que quanto maior o percentual de redução, maior a fração de martensita formada, uma vez que a mesma promove maior endurecimento no material. 


\section{Agradecimentos}

Ao Professor Luciano Pessanha da EEIMVR/UFF, que disponibilizou o ferritoscópio para este estudo. C.O.S. agracede a bolsa de doutorado e taxa de bancada oriunda do Conselho Nacional de Desenvolvimento Científico e Tecnológico (CNPq), processo de número 141571/2015-2 (Ano 2015). C.S.S. e J.M.A agradecem as bolsas de mestrado e doutorado oriundas da CAPES e FAPERJ (bolsa Aluno Nota 10), respectivamente. A.S.P. agradece a bolsa de produtividade à pesquisa (PQ-2) do CNPq (Processo 307798/2015-1).

\section{REFERÊNCIAS}

1 PADILHA AF, PLAUT RL e RIOS PR. Annealing of cold-worked austenitic stainless steels. ISIJ International. 2003;43:135-143.

2 IAWAMOTO T, TSUTA $\mathrm{T}$ e TOMITA $\mathrm{Y}$. Investigation on Deformation Mode Dependence of Strain-Induced Martensitic Transformation in TRIP Steels and Modelling of Transformation Kinetics. Elsevier Science. 1998;40:173-182.

3 COHEN M e WAYMAN MC. Fundamentals of Martensitic Reactions. Treatises in Metallurgy. 1981.

4 BEHJATI P, KERMANPUR A e NAJAFIZADEH A. Application of Martensitic Transformation Fundamentals to Select Appropriate Alloys for Grain Refining Through Martensite Thermomechanical Treatment. Metallurgical and Materials Transactions A. 2013;44A:3524-3531.

5 HAN HN. A microstructure-based analysis for transformation induced plasticity and mechanically induced martensitic transformation. Mater. Sci. Eng. A. 2008;485:224-233.

6 MARSHALL PI. Effects of alloyed molybdenum on the kinetics of repassivation on austenitic stainless steels. Elsevier applied science publishers. 1984:23-29.

7 SILVA ALVC e MEI PR. Aços e ligas especiais. 2ª Edição. Sumaré, SP: Editora Edgard Brucher; 2006.

8 PADILHA AF. Materiais de engenharia: Microestrutura e propriedades. Curitiba, PR: Editora Hemus; 2000

9 HAMADA AS, KARJALAINEN LP, MISRA RDK e TALONEN J. Contribution of deformation mechanisms to strength and ductility in two $\mathrm{cr}-\mathrm{mn}$ grade austenitic stainless steels. Materials Science \& Engineering A. 2013;559:336-344.

10 PADILHA AF e GUEDES LC. Aços inoxidáveis Austeníticos: Microestrutura e Propriedades. São Paulo, SP: Editora Hemus; 1994.

11 LEBEDEV AA. e KOSARCHUK VV. Influence of phase transformations on the mechanical properties of austenitic stainless steels. Int. J. Plasticity. 2000;16:749-767.

12 KING HW e LARBALESTIER DC. Austenitic stainless steels at cryogenic temperatures: The compositional dependence of the Ms. Cryogenics. 1981;521-522. 